\title{
Development of a Portable Electronic Sensor for Detection of the Kudzu Bug, Megacopta cribraria (Fabricius) (Hemiptera: Plataspidae)
}

\author{
Brittany D. Lampson 1* ${ }^{*}$ David C. Degenhardt², Jeremy K. Greene ${ }^{3}$, Ahmad Khalilian1, \\ Young J. Han 1 \\ ${ }^{1}$ Department of Agricultural Sciences, Clemson University, Clemson, SC, USA \\ ${ }^{2}$ Ridge View High School, Columbia, SC, USA \\ ${ }^{3}$ Department of Plant and Environmental Sciences, Clemson University, Clemson, SC, USA \\ Email: blampson@gmail.com, *akhlln@clemson.edu, yhan@clemson.edu,ddegenhardt@richland2.org, greene4@clemson.Edu
}

How to cite this paper: Lampson, B.D., Degenhardt, D.C., Greene, J.K., Khalilian, A. and Han, Y.J. (2017) Development of a Portable Electronic Sensor for Detection of the Kudzu Bug, Megacopta cribraria (Fabricius) (Hemiptera: Plataspidae). Advances in Entomology, 5, 75-86.

https://doi.org/10.4236/ae.2017.53007

Received: April 10, 2017

Accepted: June 2, 2017

Published: June 5, 2017

Copyright $\odot 2017$ by authors and Scientific Research Publishing Inc. This work is licensed under the Creative Commons Attribution International License (CC BY 4.0).

http://creativecommons.org/licenses/by/4.0/

c) $\underset{\mathrm{EY}}{0}$ Open Access

\begin{abstract}
The kudzu bug, Megacopta cribraria (Fabricius), recently became an invasive insect pest of soybean, Glycine max (L.) Merr. in the southeastern USA capable of reducing crop yield by as much as $60 \%$ if left untreated. To reduce these losses and minimize control costs, new methods for detecting kudzu bugs must be investigated in order to optimize control measures. One such method would be to detect volatiles released by kudzu bugs. An electronic portable device was developed to draw volatile organic compounds (VOCs) produced by kudzu bugs over carbon black-polymer composite sensors and measure the change in resistance for each sensor. Sensors made using polymers poly (bisphenol A carbonate) $(p=0.041)$, poly (styrene-co-allyl alcohol $)(p=0.017)$ and poly (vinylpyrrolidone) $(p=0.040)$ showed significant differences in resistance change for $M$. cribraria VOCs over the control. A logistic regression was $94.4 \%$ accurate based on the resistance changes from sensors made from polymers poly (4-vinylphenol), poly (styrene-co-allyl alcohol), and poly ( $v i-$ nylpyrrolidone) as features. These results indicate the capability of the device to detect kudzu bugs by detecting volatiles released by the insects.
\end{abstract}

\section{Keywords}

Carbon Black-Polymer Composites, Integrated Pest Management (IPM),

Megacopta cribraria, Sensors, Volatiles

\section{Introduction}

Megacopta cribraria (Fabricius) (Hemiptera: Plataspidae), commonly called the kudzu bug, was not well-known in the Western Hemisphere until it was identi- 
fied in northeast Georgia USA in mid-October 2009 [1]. In 2012, its presence was confirmed in 158 counties of Georgia, 89 North Carolina counties, all 46 counties of South Carolina, 45 Alabama counties, 19 Virginia counties, 16 Florida counties, 14 Tennessee counties, and 4 Mississippi counties [2]. Megacopta cribraria was first identified as a nuisance pest, emerging from nearby kudzu patches to aggregate on homes while looking for a place to overwinter, but it was later found infesting soybeans Glycine $\max$ (L.) Merr. [3]. In 2010, untreated $G$. max fields saw an average reduction in crop yield of 19 percent [4]. Seiter [5] reported M. cribraria densities as high as 182 nymphs and adults per plant which reduced $G$. max yields by as much as $59.6 \%$.

Since this species has emerged as an agricultural pest, its distribution within G. $\max [6]$ has been reported, sampling plans have been developed [7] [8], and action thresholds have been established [9]. Currently, the recommended sampling methods for this type of pest are sweep-net sampling and canopy observation [10]. However, because kudzu bugs are small (4-6 $\mathrm{mm}$ anterior to posterior), G. max produces no visible injury during at least a few days after feeding [3], and monitoring can be difficult. Furthermore, species of Megacopta form mating aggregations [11]. They tend to congregate with the highest concentrations on the outside rows with fewer infested plants throughout the fields [3]. This characteristic implies that it may be possible to maintain acceptable control by optimizing pesticide applications by applying pesticides only to areas that exceed a certain threshold.

The $M$. cribraria releases odors when disturbed [3]. Although the pheromones of the M. cribraria have been flagged as an important area of research, little is known about these pheromones [12]. However, plataspid species have been shown to release alarm pheromones when agitated [13]. A potential method to monitor these insects would be to exploit the volatiles released by $M$. cribraria bugs.

Carbon black-polymer composites have been used to detect natural and synthetic insect volatiles. They have been shown to increase resistance in the presence of specific volatiles [14]. Portable electronic noses that employ various types of carbon black-polymer composites and pattern recognition software are commercially available, such as the hand-held Cyranose 320 (Smith Detection, Pasadena, CA; now supplied by Sensigent, Balwin Park, CA). The Cyranose 320 has been shown to detect natural and synthetic insect volatiles [15] [16]. However, this device is expensive ( $>10,000)$, requires trained personnel for analysis, and lacks real-time software for "on-the-go" measurements of M. cribraria volatiles. Currently, there are no published data on the response of carbon black-polymer composites to M. cribraria volatiles.

The objective of this research was to develop an electronic device using carbon black-polymer composite sensors for detection of $M$. cribraria and to investigate the response of carbon black-polymer composites to $M$. cribraria volatiles. This detector would be used specifically by growers and consultants for detecting kudzu bugs and provide rapid results for in-field decision on control. Further- 
more, because optimal carbon black-polymer composites were identified for detecting kudzu bugs, our specific array of sensors will not require training, and be cheaper than commercial units ( $\$ 500$ vs. $\$ 10 \mathrm{~K}$ ).

\section{Methodology}

\subsection{Collection and Rearing of Insects}

Over 100 adults of M. cribraria were collected from fields of G. max at the Edisto Research and Education Center near Blackville, South Carolina, in June 2012, and identification of the insects were made using methods described by Benson and Greene [17]. Kudzu bugs were held in a plastic cage and fed a diet of fresh green beans. The cages were held in a controlled environment room at $30^{\circ} \mathrm{C} \pm$ $2^{\circ} \mathrm{C}$ and $70 \%$ relative humidity with a photoperiod of $14: 10$ (L:D) h.

\subsection{Fabrication of Sensors}

Carbon black-polymer composite sensors were constructed by drop coating a carbon black-polymer mixture onto a custom printed circuit board (PCB). The custom PCBs were fabricated by Pad2Pad (Mahwah, NJ) and were $29 \mathrm{~mm} \times 14$ $\mathrm{mm}$ with 4 sets of 6 interdigitated electrodes (Figure 1). The electrodes were 200 microns wide, spaced 500 microns from center to center.

Composite solutions were made using $20 \mathrm{mg}$ suspended carbon black (BP2000, Cabot Co., Billerica, MA) and $80 \mathrm{mg}$ polymer in $10 \mathrm{ml}$ solvent. Polymers used were poly (vinyl butyral), poly (4-vinylphenol), poly (bisphenol A carbonate), poly (styrene-co-allyl alcohol), poly (styrene-co-maleic anhydride), poly (vinyl acetate), poly (vinylidene chloride-co-acrylonitrile-co-methyl methacrylate) and poly (vinylpyrrolidone) (Table 1).

These polymers were chosen based on their use in previous research [14] [18]. Tetrahydrofuran was used as the solvent for all sensors. All polymers and solvents were ordered from Sigma-Adrich (St. Louis, MO). Solutions were sonicated for one minute prior to drop coating to ensure carbon black suspension

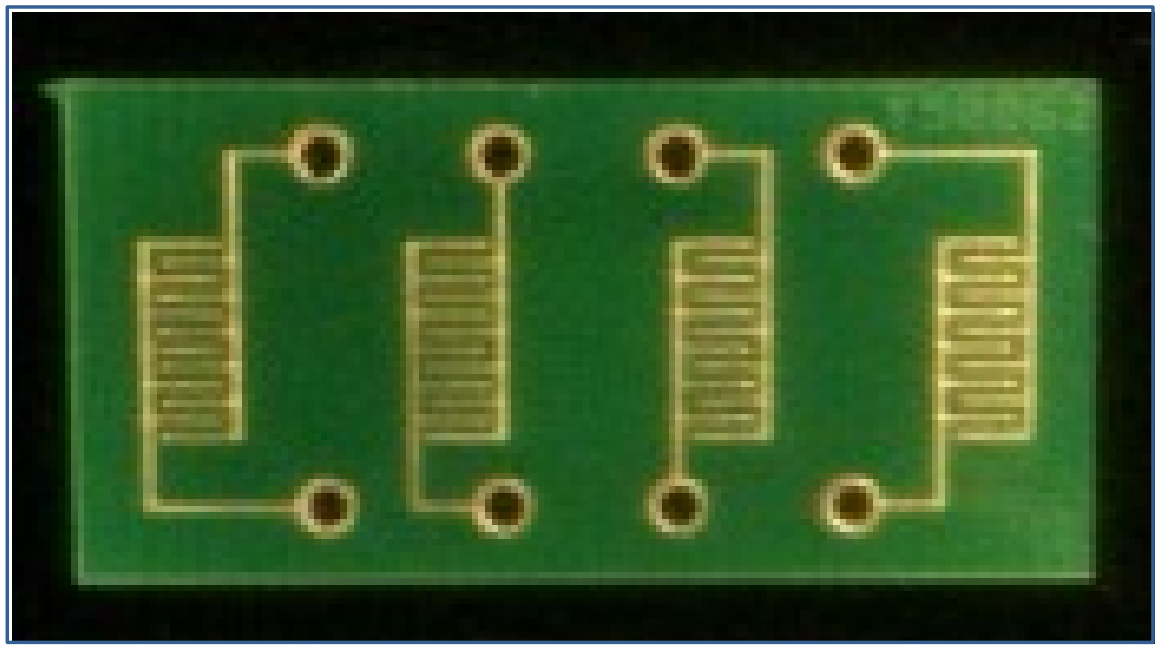

Figure 1. Printed circuit board for carbon black-polymer composite sensors. 
Table 1. Carbon black-polymer composites that were used in the sensor arrays $\alpha$ and $\beta$. Array 1, 2, and 3 corresponds to arrays $\alpha 1, \alpha 2$, and $\alpha 3$ for the sensor board $\alpha$ (sensors 1, 3, 5 , and 7); and to arrays $\beta 1, \beta 2$, and $\beta 3$ for the sensor board $\beta$ (sensors $2,4,6$, and 8 ).

\begin{tabular}{|c|c|c|c|c|c|}
\hline \multirow{2}{*}{$\frac{\text { Sensor }}{\text { No. }}$} & \multirow{2}{*}{ Polymer } & \multirow{2}{*}{ Array } & \multicolumn{3}{|c|}{ Baseline Resistance $[\mathrm{k} \Omega]$} \\
\hline & & & Array & Array 2 & Array 3 \\
\hline 1 & poly (vinyl butyral) & $\alpha$ & 1100 & 1800 & 1800 \\
\hline 2 & poly (4-vinylphenol) & $\beta$ & 1700 & 2400 & 410 \\
\hline 3 & poly (bisphenol A carbonate) & $\alpha$ & 640 & 370 & 440 \\
\hline 4 & poly (styrene-co-allyl alcohol) & $\beta$ & 210 & 340 & 600 \\
\hline 5 & poly (styrene-co-maleic anhydride) & $\alpha$ & 470 & 180 & 220 \\
\hline 6 & Poly (vinyl acetate) & $\beta$ & 180 & 550 & 170 \\
\hline 7 & $\begin{array}{l}\text { poly (vinylidene chloride-co-crylonitrile-co-methyl } \\
\text { methacrylate) }\end{array}$ & $\alpha$ & 59 & 250 & 96 \\
\hline 8 & poly (vinylpyrrolidone) & $\beta$ & 4200 & 2700 & 1700 \\
\hline
\end{tabular}

and then immediately drop coated and allowed to dry for an hour. This process was repeated until resistance was between $100 \mathrm{k} \Omega$ and $1 \mathrm{M} \Omega$. Resistance was measured with a digital multi-meter (Model 177, Fluke Corporation, Everett, WA). Final baseline resistances of the finished composite sensors ranged from $59 \mathrm{k} \Omega$ to $4.2 \mathrm{M} \Omega$ (Table 1 ).

Four sensors were assigned to array $\alpha$, and four sensors were assigned to array $\beta$. Our initial testing with sensor location on the PCBs indicated that sensor order did not affect sensor response, therefore, sensors 1,3,5, and 7 were assigned at random to array $\alpha$ in positions 1, 2, 3, and 4, respectively, with position 1 being closest to the sample input. Sensors $2,4,6$, and 8 were assigned at random to array $\beta$ in positions $1,2,3$, and 4 , respectively. Each array was replicated 3 times (3 sensor boards) for a total of 6 arrays: $\alpha 1, \alpha 2, \alpha 3, \beta 1, \beta 2$, and $\beta 3$. Arrays were replicated to study the effect of baseline resistance on sensor response.

\subsection{Development of Detector}

To develop the detector, system components (Figure 2) were assembled into an ABS enclosure (Model 100-42-NO-E, Box Enclosures and Assembly Services, Lake Bluff, IL). The micro-diaphragm pump (Model NMS020L, KNF Neuberger Inc., Trenton, NJ) was connected by $0.318 \mathrm{~cm}$ OD, $0.159 \mathrm{~cm}$ ID polyethylene tubing to a stainless steel sensor box as well as a subminiature solenoid valve (Model GH3115-C203, Gems Sensors and Controls, Plainville, CT). Approximately $58 \mathrm{~cm}$ of polyethylene tubing was used for sample collection and $16 \mathrm{~cm}$ of tubing was used for ambient air collection in total. The headers of the sensor PCB were inserted through the stainless steel sensor box and inserted into a socket on the control circuit PCB. A 12 V, 1.3 Ah AGM battery (Model WKA12-1.3F, Werker) was used as the power supply, and the MoteStack (Clemson University School of Computing, Clemson, SC) was used as the microcontroller board. The MoteStack consisted of 3 motes: the MoteStack I/O 


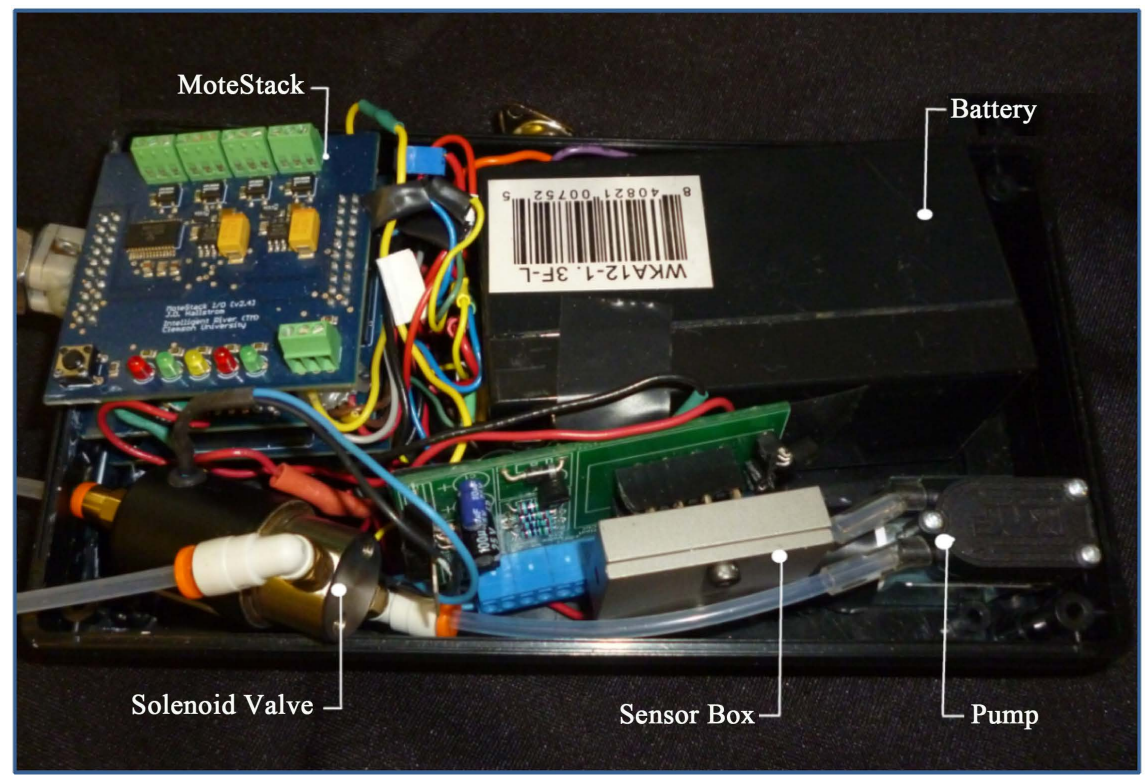

Figure 2. Components of the pest and damage detector.

board (v2.4), the MoteStack storage board (v2.2), and the MoteStack base (v2.5). The MoteStack was responsible for providing the digital output for controlling the pump and valve. Output voltages were also recorded using a data logger (midi logger GL220, Graphtec Corporation, Yokohama, Japan).

The control circuit (Figure 3) was installed on the control circuit PCB. The $12 \mathrm{~V}$ was supplied by the battery. The Mote Stack was responsible for providing the digital output for controlling the pump and valve. The sensor circuit (Figure 4) was also installed on the control circuit PCB. The Mote Stack supplied the $5 \mathrm{~V}$ and recorded the voltage drop across the carbon black-polymer composite sensors R1 to R4. In addition, for instant data visualization and better ADC resolution, a datalogger was used to record voltage drops across the sensors during the development stage. A voltage follower circuit was constructed using an LM324 operational amplifier to act as a high impedance bridge between the sensor circuit and the data logger.

\subsection{Testing of the Device}

With this system, an air stream was drawn across an array of four carbon blackpolymer composite sensors, and the change in resistance of the sensors was calculated. First, a 25-s purge cycle drew ambient air across the sensors. Then, a solenoid valve energized and redirected the air flow so it drew sample air across the sensors for a 15-s cycle. The flow rate was measured by a rotameter.

For each sample, 3 kudzu bugs were placed in $10 \mathrm{~mL}$ test tubes. Empty $10 \mathrm{~mL}$ test tubes were tested for controls. Two small holes were placed in the top of the test tubes to prevent a vacuum. The $M$. cribraria were agitated for $20 \mathrm{~s}$ to stimulate volatile production, and then the sampling tubing was inserted into one of the holes in the test tube. The sampling tube was inserted until it was within 3 $\mathrm{cm}$ of the bottom of the test tube. Ambient air was pumped and drawn over the 


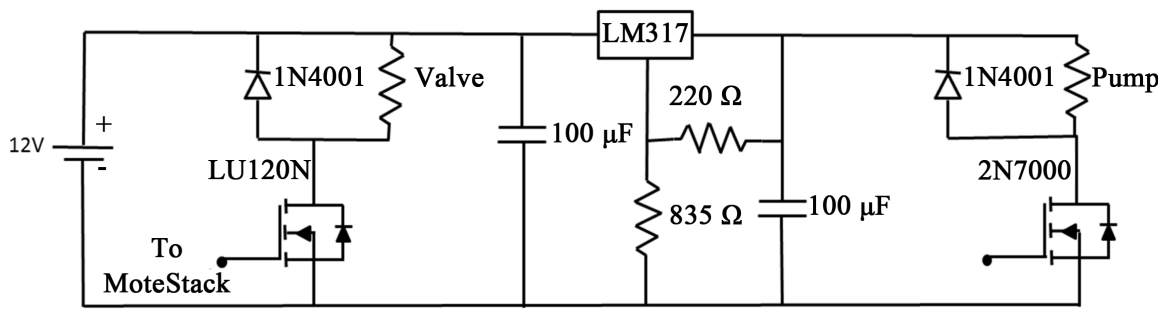

Figure 3. Control circuit for controlling the pump and valve with the MoteStack.

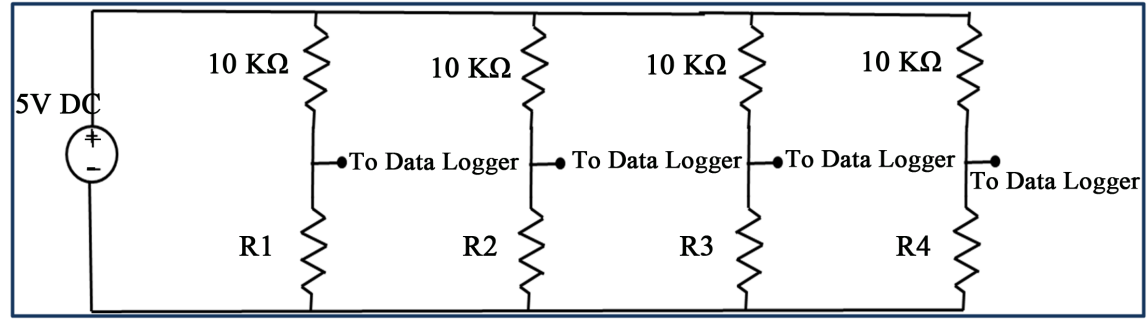

Figure 4. Sensor circuit for measuring voltage drop across the sensors. Resistors R1 - R4 represent the carbon black-polymer composite sensors.

sensors for $25 \mathrm{~s}$ to purge them. Then, the solenoid valve was activated to pump air from the test tube over the sensors for $15 \mathrm{~s}$. The flow rate of the pump under testing conditions was measured to be $20 \mathrm{~cm}^{3} / \mathrm{s}$. The total volume of the sampling tubing was calculated to be $1.2 \mathrm{~cm}^{3}$, and the total volume of the test tubes were $10 \mathrm{~cm}^{3}$. It was calculated that the entire volume of a test tube could be sampled in $0.7 \mathrm{~s}$. Three replicates were made for each sensor on each sensor array for each treatment, giving a total of nine samples for each sensor for the control treatment and nine samples for each sensor for the M. cribraria treatment.

Five analog input channels of the data logger were used. The first four input channels were used to measure the voltage drop across the carbon black-polymer sensors. The $5^{\text {th }}$ channel was used for recording the status of the solenoid valve. The voltage range for the first four input channels was $\pm 2.5 \mathrm{~V}$, and the voltage range for the $5^{\text {th }}$ channel was $\pm 5 \mathrm{~V}$. A sampling frequency of $20 \mathrm{~Hz}$ was used for all channels.

The resistance of the sensors was calculated using the voltage drop across the sensor. A calibration curve was created for each sensor position using known resistors and the Equation (1):

$$
R^{-1}=a V^{-1}+b
$$

where $R$ is the resistance of the resistor, $V$ is the voltage drop across the resistor, and $\mathrm{a}$ and $\mathrm{b}$ are constants. This calibration equation was used to account for the internal resistance of the data logger in parallel with the sensor. Baseline resistance was defined as the sensor resistance immediately after the solenoid valve was energized, maximum resistance was defined as the largest resistance measured during the sampling cycle, and percent change in resistance was calculated by dividing the difference between the maximum and baseline resistances by the baseline resistance. 
For clarity, data were graphed as a 3-period central moving average. Each point was graphed as the average of that datum point, the datum point immediately preceding it, and the datum point immediately after it. This allowed the trend of data to be observed more easily.

Percent changes in resistance of controls and $M$. cribraria volatiles were compared with a Student's t-test. Percent changes in resistance among sensor arrays were compared using ANOVA. Normality assumption was verified by histogram. A significance level of 0.05 was used for all analyses. A logistic regression was created using the percent change in resistance for each sensor in an array after a 1-s sampling cycle. Leave-one-out cross-validation was used to verify the model.

\section{Results}

Some sensors showed an increase in percent resistance change when exposed to M. cribraria volatiles as compared with ambient air (Figure 5). The only sensors to show a significant difference in change in resistance between treatments after $1 \mathrm{~s}$ of sampling were sensor $3(p=0.041)$ (Figure 6$)$, sensor $4(p=0.017)$ (Figure 7) and sensor $8(p=0.040)$ (Figure 8). No additional sensors showed a significant difference in change in resistance between treatments after $2 \mathrm{~s}$ or $15 \mathrm{~s}$ of sampling.

The logistic regression (Equation (2)) correctly identified control volatiles from $M$. cribraria volatiles with $61.1 \%$ accuracy using the percent change in resistance for sensors $1,3,5$, and 7 as features and with $77.8 \%$ accuracy using the percent change in resistance for sensors $2,4,6$, and 8 as features after a 1-s sample. However, the logistic regression correctly identified control volatiles from $M$. cribraria volatiles with $94.4 \%$ accuracy using the percent change in resis-

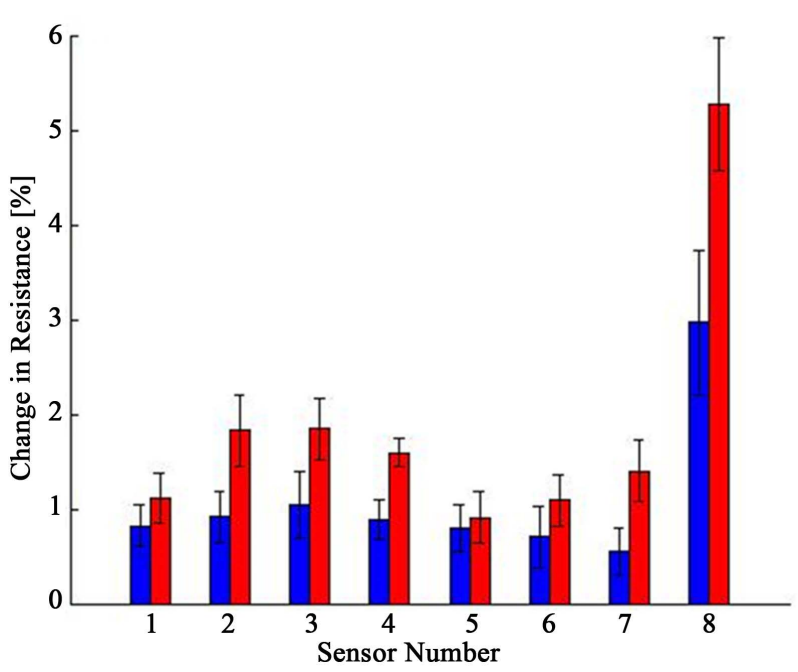

(a)

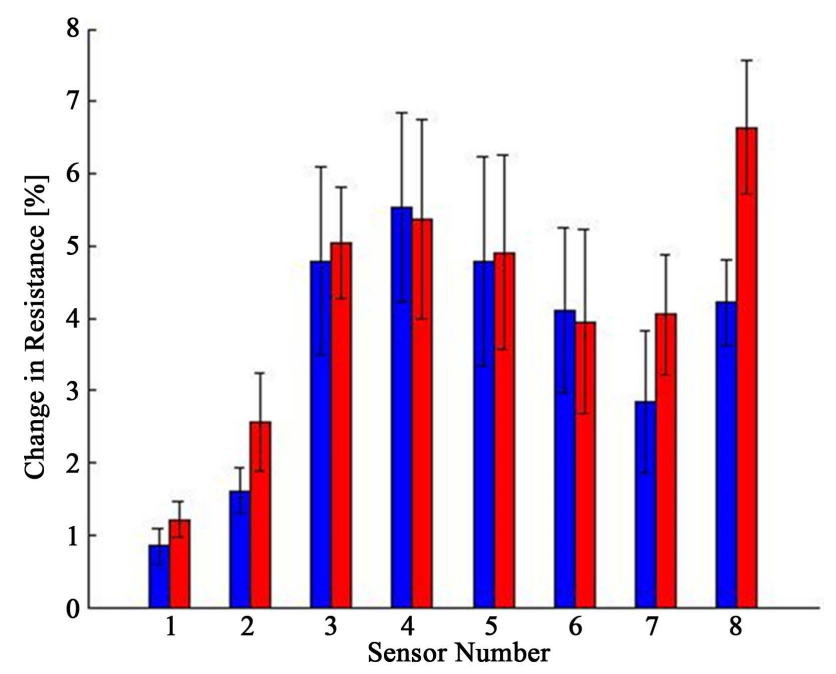

(b)

Figure 5. (a) Average sensor response to control and kudzu bugs, Megacopta cribraria (Fabricius) volatiles for all sensor arrays after 1-second sampling cycle; (b) Average sensor response to control and kudzu bugs, Megacopta cribraria (Fabricius) volatiles for all sensor arrays after 15 -second sampling cycle. Blue bars indicate control samples and red bars indicate samples of $M$. cribraria volatiles. Mean $\pm \mathrm{SE}$. 


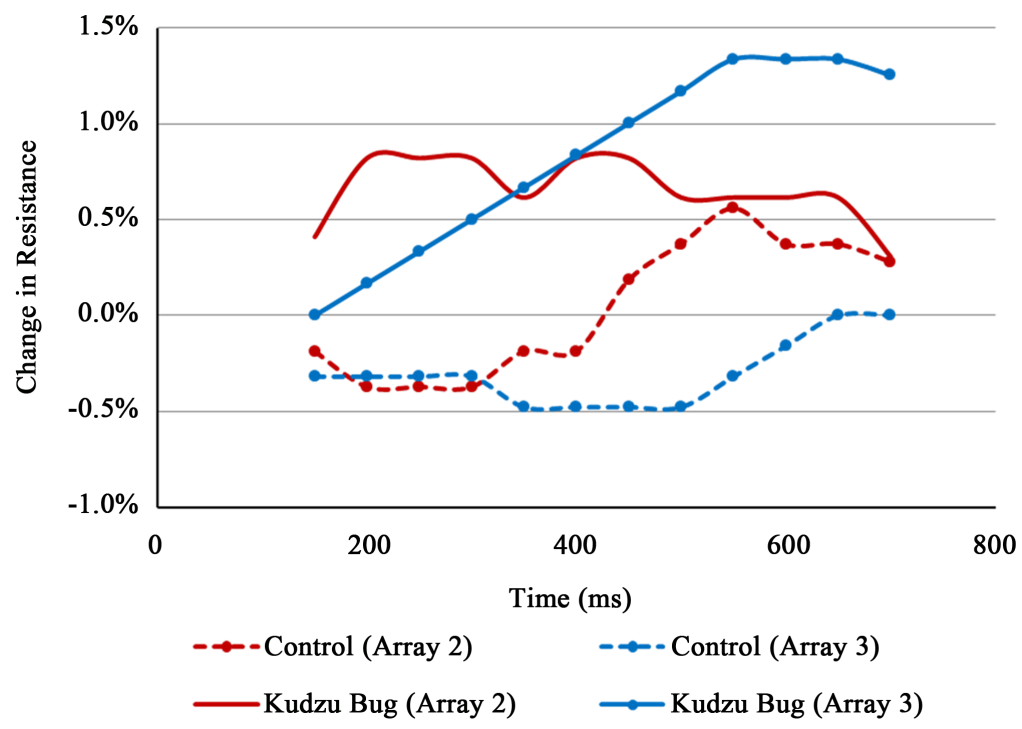

Figure 6. Typical sensor response of sensor 3 [poly (bisphenol A carbonate)] to kudzu bug, Megacopta cribraria (Fabricius) volatiles and ambient air for two sensor arrays. Data are shown as a 3 -period $(150 \mathrm{~ms})$ central moving average.

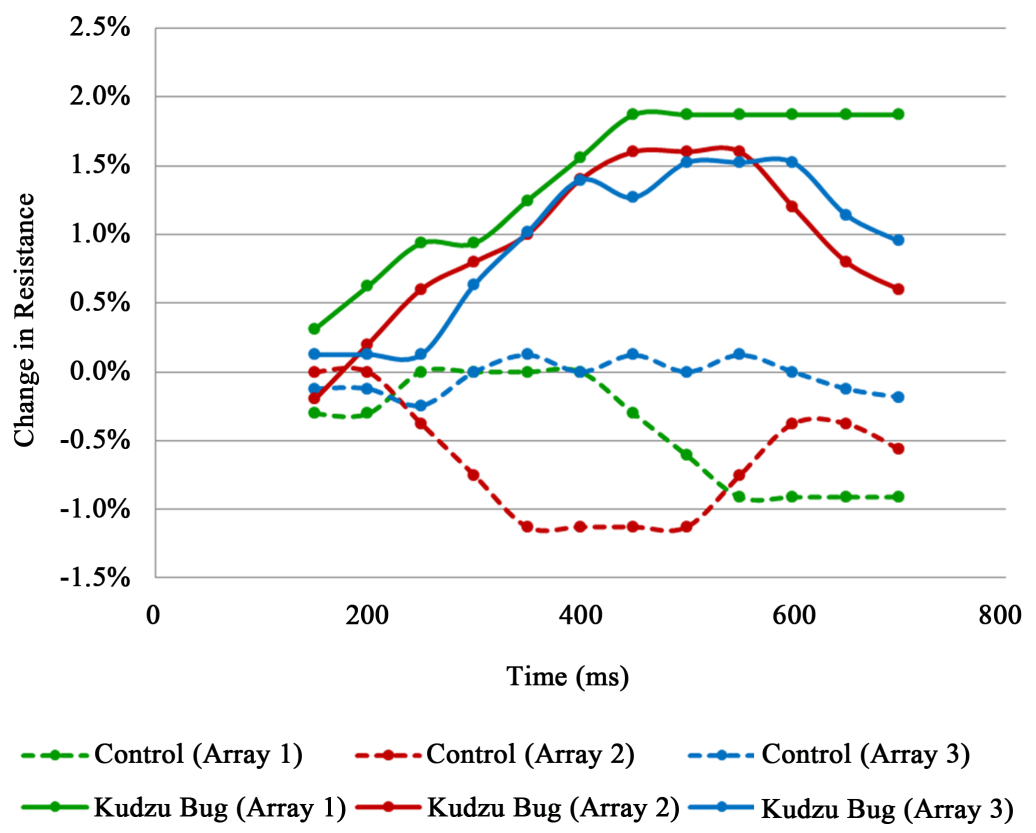

Figure 7. Typical sensor response of sensor 4 [poly(styrene-co-allyl alcohol)] to kudzu bug, Megacopta cribraria (Fabricius) volatiles and ambient air for three sensor arrays. Data are shown as a 3-period (150 ms) central moving average.

tance for sensors 2, 4, and 8 as features after $1 \mathrm{~s}$ of sampling but with only $72.2 \%$ accuracy using the percent change in resistance for sensors 4 and 8 as features after $1 \mathrm{~s}$ of sampling. The following logistic regression model was used:

$$
y=\ln \left(1+x^{\beta_{0}+\beta_{2} x_{2}+\ldots+\beta_{n} x_{n}}\right)
$$

where $y$ is probability of the VOCs belonging to a $M$. cribraria, $x_{n}$ is the percent change in resistance of the $\mathrm{n}^{\text {th }}$ sensor, and the $\beta_{0 . \mathrm{n}}$ are coefficients. If $y$ was greater 


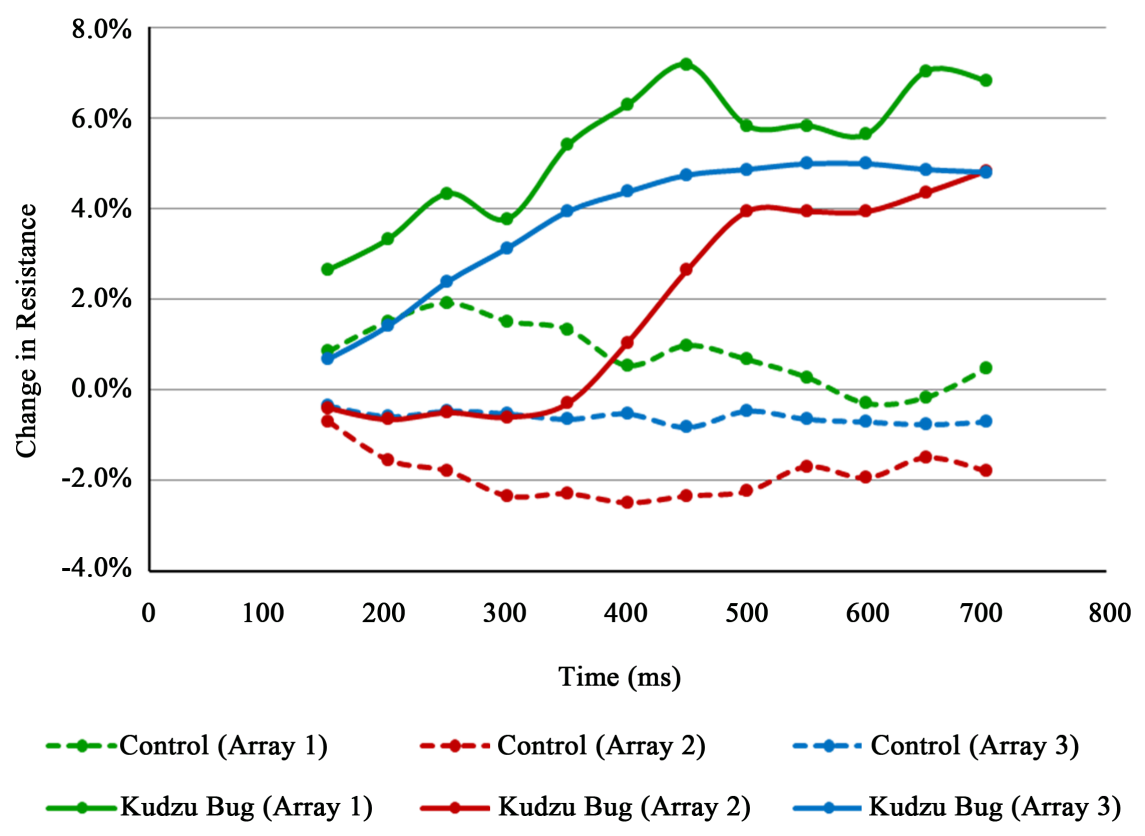

Figure 8. Typical sensor response of sensor 8 [poly(vinylpyrrolidone)] to kudzu bug, Megacopta cribraria (Fabricius) volatiles and ambient air for three sensor arrays. Data are shown as a 3 -period (150 ms) central moving average.

than or equal to 0.5 and the sample belonged to a $M$. cribraria, it was considered correctly identified. If $y$ was less than 0.5 and the sample was a control, it was also considered correctly identified.

\section{Discussion}

Results show that the most effective carbon black-polymer composite sensors were sensors 3,4 , and 8 because they showed significant differences in response to the presence of kudzu bugs after $1 \mathrm{~s}$. Because no additional sensors showed a significant change in resistance after $2 \mathrm{~s}$ or $15 \mathrm{~s}$ of sampling, it can also be concluded that only a 1-s sample is needed for detection. This short sample is likely due to the small size of the test tube in which the bugs were sampled. Because the entire test tube can be sampled in $0.7 \mathrm{~s}$ and kudzu bugs only produce volatiles when agitated and not continuously, it was predicted that only the first $0.7 \mathrm{~s}$ should show an increase in resistance. Because holes were introduced to the sampling test tube to prevent a vacuum, ambient air was able to pass into the test tube. Although the change in resistance increases for many sensors until $15 \mathrm{~s}$ of sampling (Figure 6(b)), this change in resistance after $1 \mathrm{~s}$ may be due to volatiles in the ambient air to which the sensors are responding.

Since the response of sensor 3 differed among sensor arrays for both control and $M$. cribraria volatiles samples, the response for sensor 3 was not used in sensor analyses. No other sensor response differed among sensor arrays for both control and M. cribraria volatile samples.

Insignificant differences in sensor responses between sensor arrays indicated that the fabrication method used in this study, produced sensors with reproduc- 
ible responses regardless of the baseline resistances of those sensors. Because sensor response was not significantly different for sensor arrays with different baseline resistances, it may be concluded that baseline resistance does not affect sensor response.

Because the accuracy for the logistic regression using responses from sensors 2,4 , and 8 as features was higher than the logistic regression using $2,4,6$, and 8 as features using a 1-s sample, this indicated that removing insignificant features may increase accuracy. However, because the accuracy for using features 2, 4, and 8 was higher than the accuracy for using 4 and 8, this indicated that even insignificant features might contribute to the accuracy of a multiple logistic regression for detection of these volatiles. Therefore, it can be concluded that statistical significance is not a good indicator of the contributions of various features.

Limitations of this study include fixed testing conditions where the concentration of $M$. cribraria volatiles can be assumed to be relatively constant between replicates. In field conditions, volatile concentrations may differ significantly. Therefore, future studies should examine the effect of volatile concentration on sensor response and to determine the detection limit of sensors to known concentrations of $M$. cribraria volatiles, and/or ability of sensors to respond to $M$. cribraria densities in "open air" or "field conditions".

\section{Conclusions}

This research showed the potential of using carbon black-polymer composites for detecting volatiles from kudzu bugs and the potential for development of a portable electronic nose that is able to detect volatiles emitted from the species within a 1-s sampling cycle. It also shows the potential for a multiple logistic regression to detect these volatiles.

Limitations of this study include fixed testing conditions where the concentration of M. cribraria volatiles can be assumed to be relatively constant between replicates. In field conditions, volatile concentrations may differ significantly. Therefore, future studies should examine the effect of volatile concentration on sensor response and to determine the detection limit of sensors to known concentrations of $M$. cribraria volatiles, and/or ability of sensors to respond to $M$. cribraria densities in "open air" or "field conditions".

\section{Recommendation}

Further research may include the use of carbon black-polymer composites for distinguishing volatiles from various insects. To increase accuracy of detection, carbon black-polymer composites using additional polymers and methods to decrease sensor response to ambient air may be investigated. For example, the addition of a filter on the ambient air intake may increase the accuracy of the device. Also, investigating shorter purging cycles may decrease total testing time. Also, the MoteStack can be upgraded to provide additional features, such as wireless data transmission via various interfaces (i.e., cellular, WiFi, Zigbee). 


\section{Acknowledgements}

Technical Contribution No. 6552 of the Clemson University Experiment Station. This material is based upon work supported by NIFA/USDA, under Project number SC-1700498, SC-1700470, and SC-1700512.

\section{Disclaimer}

Mention of a trade name does not imply endorsement of the product by Clemson University to the exclusion of others that might be available.

\section{References}

[1] Eger, J.E., Ames, L.M., Suiter, D.R., Jenkins, T.M., Rider, D.A. and Halbert, S.E. (2010) Occurrence of the Old World Bug Megacopta cribraria (Fabricius) (Heteroptera: Plataspidae) in Georgia: A Serious Home Invader and Potential Legume Pest. Insecta Mundi, 121, 1-11.

[2] UGA-CISEH (2012) Kudzu Bug-Distribution Map. University of Georgia-Center for Invasive Species and Ecosystem Health.

https://www.kudzubug.org/distribution-map/

[3] Suiter, D.R., Eger, J.E., Gardner, W.A., Kemerait, R.C., All, J.N., Roberts, P.M., Greene, J.K., Ames, L.M., Buntin, G.D., Jenkins, T.M. and Douce, G.K. (2010) Discovery and Distribution of Megacopta cribraria (Hemiptera: Heteroptera: Plataspidae) in Northeast Georgia. Journal of Integrated Pest Management, 1, F1-F4. https://doi.org/10.1603/IPM10009

[4] Shepard, P. (2012) Kudzu Bug Making Inroads in Southeast Soybeans. Southeast Farm Press.

[5] Seiter, N.J., Greene, J.K. and Reay-Jones, F.P.F. (2013) Reduction of Soybean Yield Components by Megacopta cribraria (Hemiptera: Plataspidae). Journal of Economic Entomology, 106, 1676-1683. https://doi.org/10.1603/EC13121

[6] Seiter, N.J., Reay-Jones, F.P.F. and Greene, J.K. (2013) Within-Field Spatial Distribution of Megacopta cribraria (Hemiptera: Plataspidae) in Soybeans. Environmental Entomology, 42, 1363-1374. https://doi.org/10.1603/EN13199

[7] Stubbins, F.L., Seiter, N.J., Greene, J.K. and Reay-Jones, F.P.F. (2014) Developing Sampling Plans for the Invasive Megacopta cribraria (Hemiptera: Plataspidae) in Soybean. Journal of Economic Entomology, 107, 2213-2221. https://doi.org/10.1603/EC14203

[8] Stubbins, F.L., Greene, J.K., Toews, M.D. and Reay-Jones F.P.F. (2016) Assessment of a Cross-Vane Trap as a Tool for Sampling the Invasive Megacopta cribraria in Soybean with Associated Evaluations of Female Reproductive Status. Environmental Entomology, 45, 1262-1270. https://doi.org/10.1093/ee/nvw113

[9] Seiter, N.J., Del Pozo-Valdivia, A.I., Greene, J.K., Reay-Jones, F.P.F., Roberts, P.M. and Reisig, D.R. (2015) Action Thresholds for Managing Megacopta cribraria (Hemiptera: Plataspidae) in Soybean Based on Sweep-Net Sampling. Journal of Economic Entomology, 108, 1818-1829. https://doi.org/10.1093/jee/tov171

[10] Seiter, N.J., Greene, J.K., Roberts, P.M., Gardner, W.A. and Reay-Jones, F. (2014) Kudzu Bug: Current Status and Management in Soybeans. United Soybean Board Technology Transfer Publication. United Soybean Board, Chesterfield. http://reader.mediawiremobile.com/USB/issues/107145/viewer

[11] Hibino, Y. and Itô, Y. (1983) Mating Aggregation of a Stink Bug, Megacopta punctissimum (Montandon) (Heteroptera: Plataspidae). Researches on Population 
Ecology, 25, 180-188. https://doi.org/10.1007/BF02528791

[12] Akin, S., All, J., Allen, C., Boerma, R., Buntin, D., Cardinal, A., Catchot, A., Chen, P., Clough, S., Cook, D., Davis, J., Dively, G., Greene, J., Herbert, A., Herbert, J., Heitholt, J., Jones, W., Leonard, R., Lorenz, G., Miranda, L., Musser, F., Reed, T., Reisig, D., Roberts, P., Smith, R., Stewart, S. and Way, M. (2011) A Strategy for Prioritizing Research Goals and Outreach Plans to Reduce Soybean Production Losses Caused by Stink Bugs and Related Insect Pests. SoyBase. USDA ARS.

[13] Dejean, A., Orivel, J. and Gibernau, M. (2002) Specialized Predation on Plataspid 9 Heteropterans in a Coccinellid Beetle: Adaptive Behavior and Responses of Prey Attended or Not by Ants. Behavioral Ecology, 13, 154-159. https://doi.org/10.1093/beheco/13.2.154

[14] Lonergan, M.C., Severin, E.J., Doleman, B.J., Beaber, S.A., Grubbs, R.H. and Lewis, N.S. (1996) Array-Based Vapor Sensing Using Chemically Sensitive, Carbon Black-Polymer Resistors. Chemistry of Materials, 8, 2298-2312. https://doi.org/10.1021/cm960036j

[15] Henderson, W.G., Khalilian, A., Han, Y.J., Greene, J.K. and Degenhardt, D.C. (2010) Detecting Stink Bugs/Damage in Cotton Utilizing a Portable Electronic Nose. Computers and Electronics in Agriculture, 70, 157-162.

[16] Suh, C.P., Ding, N. and Lan, Y. (2011) Using an Electronic Nose to Rapidly Assess Grand Lure Content in Boll Weevil Pheromone Lures. Journal of Bionic Engineering, 8, 449-454.

[17] Benson, E.P. and Jeremy, K.G. (2012) Kudzu Bugs around the Home. EIIS/HS-50, Clemson University.

http://www.clemson.edu/extension/publications/entomology/household-structural/ kudzu-bugs-hs50.html

[18] Weerakoon, K.A. and Chin, B.A. (2010) Detecting Insect Infestation Using a Carbon/Polymer Composite Based Sensor Array. ECS Transactions, 33, 85-89.

\section{Submit or recommend next manuscript to SCIRP and we will provide best service for you:}

Accepting pre-submission inquiries through Email, Facebook, LinkedIn, Twitter, etc. A wide selection of journals (inclusive of 9 subjects, more than 200 journals)

Providing 24-hour high-quality service

User-friendly online submission system

Fair and swift peer-review system

Efficient typesetting and proofreading procedure

Display of the result of downloads and visits, as well as the number of cited articles

Maximum dissemination of your research work

Submit your manuscript at: http://papersubmission.scirp.org/

Or contact ae@scirp.org 